\title{
FUNDAMENTALISME AGAMA \\ Telaah Artikel "Religious Fundamentalism" dalam Buku Introducing Anthropology of Religion; Culture of the Ultimate \\ Karya Jack David Eller
}

\author{
Nur Kholis \\ Universitas Islam Nahdlatul Ulama (UNISNU) Jepara \\ Jl. Taman Siswa, Tahunan, Jepara, Jawa Tengah, 59427 \\ Email: nurkholis@unisnu.ac.id
}

\begin{abstract}
The discussion in the article "Religious Fundamentalism" has a background in the development of the global cultural situation in the 20th and 21st centuries which shows an atmosphere of "tension" due to the encounter of religion with modern culture and secularity. Religion seemed to feel threatened by modernity so that it carried out self-defense and simultaneously resisted. As a result of being confined to tension that is actually "self-created", according to Eller, religious fundamentalism appears with a ferocious, vindictive and sometimes violent character. This kind of character is increasingly entrenched for those who have similar emotions, attitudes, and puritanical religious orientations. The main message Eller conveyed is that religious fundamentalism is not a single and stand-alone phenomenon, but is interrelated with other cultural factors with high complexity.
\end{abstract}

Key Words: Religious, Fundamentalism, globalization, anthropology, Jack David Eller

\section{Pendahuluan}

Artikel yang berjudul "Religious Fundamentalism" merupakan salah satu bab (yakni bab 11) dari 12 bab dalam buku Introducing Anthropology of Religion; Culture of the Ultimate Karya Jack David Eller oleh Penerbit Madison Ave. New York (2007). Artikel setebal 26 halaman ini, terletak pada halaman ke 275-301, memaparkan bagaimana fundamentalisme memiliki potensi untuk hidup dan berkembang dalam setiap agama. Eller bahkan memastikan bahwa tidak ada agama manapun yang terbebas dari fundamentalisme. Namun demikian, ia berkali-berkali menegaskan bahwa fundamentalisme juga dapat tumbuh dan berkembang dalam unsur budaya manapun; termasuk dalam hal budaya politik, ekonomi, ras, dan lebih-lebih agama.

Paparan mengenai kemunculan fundamentalisme agama dalam artikel ini dikaitkan erat dengan adanya budaya modern dan sekularitas, di mana fundamentalisme tampil sebagai "gerakan perlawanan" untuk membangun ideologi tertentu ke dalam komunitasnya sekaligus menentang serta berusaha menyingkirkan pihak-pihak di luar dirinya yang dipandang modern, liberal dan sekular.

Pemaparan Eller tentang fundamentalisme bukan hanya sebatas penjelasan teoretik dan berdasar pada pustaka, melainkan dibuktikan dengan studi kasus di lapangan terutama yang terjadi pada agama Kristen dan Islam. Fundamentalisme agama diuraikan 
bagaimana terjadi pada agama Kristen, Yahudi, Islam, Hindu, dan Budha.

Pembahasan dalam artikel ini disistematisasikan ke dalam sub-sub bahasan berdasarkan fokus pembicaraan dari arah mana fundamentalisme secara umum, atau fundamentalisme agama secara khusus, dilihat. Namun demikian, sebagaimana buku ini dimaksudkan, sorotan antropologi memang sangat terasa kental dalam pembahasannya. Hal ini semakin menegaskan bahwa artikel beserta buku ini memang secara keseluruhan sedang berperan dalam memperkenalkan antropologi sebagai suatu pendekatan.

\section{Formulasi Artikel "Religious Fundamentalism"}

\subsection{Latar dan Tujuan}

Diskusi dalam artikel "Religious Fundamentalism" berlatar belakang perkembangan situasi budaya global pada abad ke-20 dan ke-21 yang menunjukkan suasana "tegang" akibat perjumpaan agama dengan budaya modern dan sekularitas. Agama seolah merasa terancam oleh modernitas sehingga melakukan pertahanan diri dan sekaligus melakukan perlawanan. Akibat terkungkung dalam ketegangan yang sebenarnya "diciptakan sendiri", menurut Eller, fundamentalisme agama tampil dengan watak garang, pendendam, dan kadang-kadang melakukan kekerasan. Watak semacam ini semakin membudaya bagi kalangan yang memiliki kesamaan emosi, sikap, serta orientasi keagamaan yang puritan. Dengan kata lain, semakin puritan suatu pemahaman keagamaan maka semakin mudah ditemukan indikator-indikator fundamentalisme.

Latar belakang semakin menguat mengingat fundamentalisme agama memiliki misi tidak hanya diam-bertahan, melainkan melawan dengan kecenderungan merusak pihak lain, dan bahkan bercita-cita meraih kekuasaan untuk mengembangkan pemahamannya.
Dalam ungkapan lain, fundamentalisme agama bukan anti terhadap kekuasaan yang ada, akan tetapi sebenarnya sedang berjuang merebut kekuasaan itu sendiri.

Adapun tujuan penulisan artikel ini adalah untuk memperkenalkan dan membuktikan bahwa antropologi merupakan alat/ pendekatan yang dapat diandalkan dalam melakukan pembacaan dan analisis multi perspektif terhadap peristiwa budaya, termasuk di dalamnya budaya dalam menjalankan agama. Sebagaimana ingin ditunjukkan oleh Eller, bahwa fundamentalisme agama bukanlah suatu fenomena tunggal dan berdiri sendiri, tetapi saling terkait dengan faktor budaya lainnya dengan kompleksitas yang tinggi.

\subsection{Pokok Masalah}

Pokok masalah dalam artikel ini adalah fundamentalisme dalam agama. Pertanyaan apa, siapa, mengapa, bagaimana, serta kapan fundamentalisme agama muncul merupakan persoalan pokok yang diulas. Permasalahan diposisikan bukan hanya sebagai persoalan kekinian, melainkan juga dibaca sebagai "akibat" dari masa sebelumnya sekaligus dipertimbangkan sebagai "sebab" bagi keadaan masa yang akan datang. Dengan kata lain, fundamentalisme agama hendak didudukkan sebagai persoalan budaya yang abadi sepanjang sejarah hidup manusia.

\subsection{Metode dan Sistematika}

Secara keseluruhan, artikel ini didasarkan pada data, dianalisis serta ditulis dengan metode kualitatif yang berpola induktif, di mana fenomena dan kasus-kasus di lapangan yang bersifat partikular, temporal, dan sektoral disusun menuju titik temu tertentu, kemudian disusun ke dalam sebuah konsep baru yang universal (Danim, 2010). Kejadiankejadian yang tersebar dengan 
keunikannya masing-masing tersebut, yang berasal dari fenomena lintas agama serta berasal dari berbagai wilayah dunia, dipertemukan ke dalam satu tema fundamentalisme agama.

Sistematika pemaparan artikel ini berbentuk deskriptif dengan pola bebas. Artinya, pembahasan dilakukan tidak dengan alur yang ketat, teratur, atau dengan pola kejurnalan yang kaku, melainkan disusun dengan asas kebutuhan pragmatis dengan mempertimbangkan fokus dan kelezatan penyuguhan, sehingga tampaknya dimaksudkan agar mudah dipahami oleh pembaca.

Sistematika tersebut tersusun dengan ulasan sebagaimana berikut: Antropologi Fundamentalisme; Fundamentalisme, "Tradisi", dan Modernitas; Fundamentalisme sebagai Sistem Budaya; Fundamentalisme Kristen; Munculnya Fundamentalisme Modern; Kebangkitan Fundamentalisme di Akhir Abad ke-20; Fundamentalisme dalam Perspektif Lintas Budaya; Fundamentalisme Yahudi; Fundamentalisme Islam; Fundamentalisme Hindu; Fundamentalisme Buddhis; dan, Kesimpulan.

\section{Cakupan Antropologi dalam Artikel "Religious Fundamentalism"}

\begin{abstract}
Memasukkan fundamentalisme agama dalam kajian antropologi merupakan tema yang rumit dan kompleks. Sebagaimana dinyatakan oleh Eller bahwa fundamentalisme agama bukan suatu fenomena di ruang kosong, melainkan terkait erat dengan unsur-unsur budaya lainnya dalam sejarah peradaban manusia.
\end{abstract}

Menyitir pandangan antropologi Nur Syam (2007: 37-42), ${ }^{1}$ kajian

1 Di dalamnya disebutkan nama tokohtokoh antropologi kognitif ini di antaranya Niels Mulder (kosakata sebagai tindakan), Ben Anderson (wayang sebagai pedoman hidup orang Jawa), dan fundamentalisme agama yang dilakukan Eller sebenarnya termasuk dalam kategori "antropologi kognitif", yaitu di mana budaya dipandang sebagai "pengetahuan" yang mengungkap isi pikiran, nalar, emosi, perasaan, dan keyakinan di balik material (seperti bahasa, ritual, perilaku).

Pandangan yang populer dalam skala global didominasi oleh tayangan fundamentalisme Kristen dan Islam, yang digambarkan bahwa seorang fundamentalis adalah "orang saleh (evangelis) yang secara militan menentang teologi liberal dan beberapa aspek sekularisme budaya modern." Di samping itu, tidak semua fundamentalisme agama memiliki tujuan yang sama atau mereka juga mengadopsi metode yang sama. Dan, tentu saja, tidak semua fundamentalisme adalah agama itu sendiri.

Dalam catatan Eller, karakteristik fundamentalisme agama dapat disimpulkan sebagai berikut:

1. Memiliki nalar dan gerakan purifikasi;

2. Klaim agama sebagai basis yang dapat direduksi untuk identitas komunal dan pribadi;

3. Eksklusifisme-Ekstremisme;

4. Eskatologi dramatis;

5. Dramatisasi, bahkan "mitologi" musuh-musuh mereka;

6. Orientasi kontra terhadap "budaya", yaitu, penolakan untuk berkompromi dengan atau mengintegrasikan pengaruh luar;

7. Semangat misionaris;

8. Mentalitas krisis seolah sedang dilanda tekanan;

9. Kepemimpinan yang karismatik dan otoriter (biasanya laki-laki);

10. Mobilisasi massa;

11. Penolakan modernitas namun tidak konsisten.

WH. Goodenough (kebudayaan adalah pemikiran, bukan material). 
Item terakhir ini memunculkan benang merah dari fundamentalisme, yang disebut Eller sebagai kesimpulan dari sudut pandang antropologi, yaitu dugaan perlawanan terhadap "yang sekarang" atau "yang modern". Sebagai suatu jenis gerakan, ia secara terbuka menarik diri ke "masa lalu" atau "tradisi." Fundamentalisme mengingat kembali secara kuat-kuat ke waktu sebelumnya, waktu yang lebih dekat ke asal mula agama dilahirkan, ketika keyakinan dan praktik agama diakuinya lebih sempurna.

Fundamentalisme

agama

kemudian diilustrasikan oleh Eller dengan dua gambaran umum. Pertama, fundamentalisme agama adalah untuk "membentuk sesuatu", yaitu yang membentuk pandangan dunia dan kebenaran bagi para praktisinya. Misalnya, pandangan yang memastikan kebenaran ajaran agama terbebas dari hiruk-pikuk duniawi yang dijamin kepastiannya bahwa jalan mereka adalah jalan yang paling benar, oleh karena itu kritik dari orang lain dianggap sebagai korup dan sesat.

Kedua, fundamentalisme agama "menentang sesuatu". Hampir semua model fundamentalisme agama menekankan sikap yang eksklusif, gelisah, dan bahkan militan. Dalam pencermatan Eller, seorang fundamentalis harus tidak hanya percaya ajaran-ajaran suci mereka, tetapi mereka harus bersedia untuk berjuang melawan teologi modernis, humanisme sekuler, dan sejenisnya. Kaum fundamentalis melihat diri mereka sebagai militan yang selalu melawan dalam fase kehidupan yang penuh perkelahian; baik dengan kata, ide, surat suara pemilu, bahkan dalam kasus ekstrim, menjadi peluru. Hal inilah yang membuat mereka tetap hidup terlihat berada di bawah ancaman.

Fundamentalisme agama kontemporer adalah jenis gerakan keagamaan yang menyangkal bahwa ia adalah gerakan keagamaan baru. Sebaliknya, ia menganggap dirinya sebagai agama lama, agama yang dipulihkan, bukan hanya dibawa kembali untuk hidup tetapi juga membawa kembali keunggulan budaya lama dalam budaya masyarakat sekarang.

Dalam pencermatan Eller, fundamentalisme agama berdiri dalam hubungan ambigu dengan modernitas. Mereka terang-terangan dan terus terang menolak banyak aspek modern atau yang disebutnya asing (atau keduanya). Sikap, praktik, maupun nilai-nilai dunia modern mereka anggap sebagai musuh yang nyata, bahkan ketika mereka menerima atau menggunakannya. Fundamentalis masih dengan senang hati memanfaatkan percetakan, komputer, internet, telepon seluler, dan banyak lagi barang-barang modernitas lainnya. Namun di saat bersamaan, mereka merekomendasikan berbicara dengan bahasa kitab suci mereka masing-masing, memakai jubah, serta menonjolkan simbol agama yang diyakininya klasik. Ini menjelaskan karakteristik "modernisasi selektif," di mana gerakan tersebut bersaing dengan tetapi juga beradaptasi dengan modernitas yang mereka anggap musuh.

Fenomena ambiguitas dalam fundamentalisme agama yang dimaksud Eller tampaknya memang masih dengan mudah dapat ditemukan. Akan tetapi, sebagaimana dalam temuan Asef Bayat (2011) tentang fundamentalisme Islam, ambiguitas tersebut mulai bergerak ke arah sikap baru yang berbeda dan bahkan berbalik dari sebelumnya. Gejala gerakan baru dari fundamentalisme Islam ini disebut Bayat sebagai Pos-Islamisme.

Pos-Islamisme adalah sebuah terminologi baru untuk menggambarkan sebuah fenomena baru dalam gerakan politik Islam di kalangan muslim garis keras di negara-negara Timur Tengah, terutama Iran. Fenomena baru itu adalah berupa keikutsertaan dan partisipasi mereka dalam sistem politik modern/nasional, yang sebelumnya oleh mereka dianggap sebagai sistem politik yang tidak Islami. Partisipasi mereka 
dalam politik nasional bisa berupa peningkatan hak suara pada Pemilu, afiliasi terhadap partai politik tertentu, bahkan bisa pula membentuk partai politik yang (sama sekali) baru. Pos-Islamisme merupakan kategori paradigmatik baru tentang gerakan politik fundamentalsime agama. Artinya, telah terjadi perubahan paradigma dan gerakan politik fundamentalisme agama di kalangan muslim garis keras, dari yang militan, eksklusif, dogmatis, ke arah paradigma dan gerakan yang menghargai inklusivitas, pluralitas, dan toleransi (Bayat, 2011: 16-18).

Meskipun demikian, sebagaimana disimpulkan Eller, tidak ada agama yang kebal terhadap kecenderungan fundamentalisme, terutama di alam pluralisme agama dan budaya, perubahan sosial yang cepat, dan keyakinan agama yang kuat dan sarat sentimen. Semua fundamentalisme memiliki sifat reaksioner atau defensif tertentu-bahkan militansi tertentu-meskipun reaksi mereka juga bervariasi antar masyarakat atau negara dan juga agama. Mereka juga tidak benar-benar unik untuk ukuran zaman modern, tetapi dapat ditemukan di setiap perubahan zaman. Mereka adalah salah satu dari bentuk-bentuk "gerakan revitalisasi" yang muncul di semua masyarakat (dan tidak hanya di lembagalembaga keagamaan) selama saat-saat kesenjangan sosial terjadi.

Dengan demikian, juga disimpulkan oleh Eller, fundamentalisme bukan "agama yang buruk" juga bukan "agama yang benar", melainkan salah satu variasi yang kemungkinan dapat terjadi dalam bungkus agama tertentu dan dalam keadaan sosial tertentu. Fakta bahwa keadaan ini dipastikan berlanjut dan bahkan lebih intensif di masa depan menunjukkan bahwa fundamentalisme mungkin akan terus bertahan selamanya. Hal ini membuktikan bahwa modernitas sebenarnya bukanlah kematian agama tetapi hanya cukup disikapi dengan lebih baik.

\section{Beberapa Keterbatasan Artikel "Religious Fundamentalism"}

Setelah mencermati, reviewer menemukan beberapa hal yang sekiranya menjadi kekurangan artikel "Religious Fundamentalism" karya David Jack Eller. Pertama, uraian mengenai fundamentalisme agama dalam artikel ini seringkali berulang-ulang pada penekanan pesan yang sama, bahkan dengan kalimat dan diksi yang cenderung sama. Hal ini memang tidak mengurangi substansi pembahasan, akan tetapi menimbulkan kesan bahwa penulis sedang "menjejalkan" narasi tunggal kepada pembaca. Sebagai akibatnya, pembaca berpotensi menjadi mudah jenuh karena menemukan kalimat penjelasan yang hampir sama berkali-kali dalam satu artikel (sub bab) dalam sebuah buku.

Kedua, perspektif yang digunakan Eller masih cenderung ke arah perspektif epik, bukan perspektif emik. Hal ini terlihat dari kesan yang dibangunnya dengan memposisikan fundamentalisme agama sebagai pihak anatagonis semata dalam tatanan dunia global. Fundamentalis agama belum diposisikan sebagai "subjek yang bicara" namun cenderung sebagai "objek yang dibaca" menurut perspektif peneliti. Meskipun demikian, kesan semacam ini menjadi sedikit "terlupakan" setelah pada bagian akhir tulisannya Eller menyatakan bahwa fundamentalisme agama bukan "agama yang buruk" juga bukan "agama yang benar," melainkan hanyalah variasi kehidupan sosial.

Ketiga, jika ditinjau dari sudut paradigma penelitian, artikel Eller ini termasuk kategori paradigma pascapositivisme, di mana penulis-peneliti menguraikan temuan secara deskriptif serta "berjarak" tanpa adanya konstruksi pemahaman baru versi objek kajian, apalagi keberpihakan terhadapnya. Sebagaimana dijelaskan John W. Creswell (2013: 6-16), kunstruksi temuan yang pro- 
objek hanya memungkinkan dibangun dengan paradigma konstruktivisme, sedangkan pembelaan dan keinginan merubah nasib objek hanya dapat dilakukan dengan paradigma advokatifpartisipatoris. Dengan kata lain, jika bukan sebagai cerminan paradigma pospositivisme, paradigma dalam artikel ini lebih condong kepada paradigma pragmatisme yang bermaksud sebatas "memaparkan sesuatu."

Keempat, pandangan antropologi Eller mengenai fundamentalisme agama mengikuti "arus besar" konsepsi fundamentalisme dalam literasi global. Eller dalam analisisnya sama sekali tidak menyinggung aspek politik kemunculan fundamentalisme yang dalam pandangan tertentu sengaja dimunculkan oleh imperialisme. Dalam artikel ini, fundamentalisme agama dipahami Eller sebagai sesuatu yang natural dan terlepas dari rekayasa (politik budaya), apalagi konspirasi. $^{2}$

2 Dalam kenyataannya, Islam
Fundamentalisme Modern adalah bikinan John
Foster Dulles, menteri luar negeri AS pada masa
Presiden Eisenhower. CIA meluncurkan sebuah
operasi untuk mensponsori, mendanai, dan
mendukung pembentukan kelompok-kelompok
Islam yang dapat memainkan peran yang
reaksioner terhadap rezim-rezim Kiri,
kecenderungan-kecenderungan anti-imperialis
yang penting, dan - dalam beberapa kasus -
perjuangan-perjuangan anti-kapitalis, di Dunia
Muslim. Ikhwanul Muslimin di Timur Tengah dan
Jamaah Islamiyah di Asia Selatan serta Masjumi
dan Nahdlatul Ulama in Indonesia adalah contoh-
contoh organisasi yang didirikan untuk melindungi
kapitalisme di negeri-negeri tersebut. Kekuatan-
kekuatan obskurantisme agamawi digunakan oleh
para tentara pro-imperialis dalam pembantaian
massal yang digelar di Indonesia pada akhir 1965
dan di Bengali Timur pada tahun 1971.
Imperialisme selalu menggunakan agama untuk
melaksanakan kebijakan "pecah belah dan kuasai "
(divide et impera) di berbagai belahan dunia. Lihat
Lal Khan, "Religious Fundamentalism and
Imperialism - Friends or Foes?", dalam Pandu
Jakasurday, https://www.militanindonesia.org/
internasional/ asia/ pakistan/8175-
fundamentalisme-agama-dan-imperialisme-kawan-
atau-lawan.html, akses 10 Oktober 2018.

\section{DAFTAR PUSTAKA}

Bayat, Asef. 2011. Pos-Islamisme. Terj. Faiz Tajul Milah. Yogyakarta: LKiS.

Creswell, John W. 2013. Research Design: Pendekatan Kualitatif, Kuantitatif, dan Mixed. Terj. Achmad Fawaid. Yogyakarta: Pustaka Pelajar.

Danim, Sudarwan. 2010. Menjadi Peneliti Kualitatif. Bandung: Pustaka Setia.

Eller, Jack David. 2007. Introducing Anthropology of Religion; Culture of the Ultimate, New York: Madison Ave.

Khan, Lal. "Religious Fundamentalism and Imperialism; Friends or Foes?", dalam Pandu Jakasurday, https://www.militanindonesia.org/ internasional/ asia/ pakistan/8175fundamentalisme-agama-danimperialisme-kawan-ataulawan.html, akses 10 Oktober 2018.

Syam, Nur. 2007. Madzhab-Madzhab Antropologi. Yogyakarta: LKiS. 


\section{LAMPIRAN}

\section{Halaman sampul depan/luar}

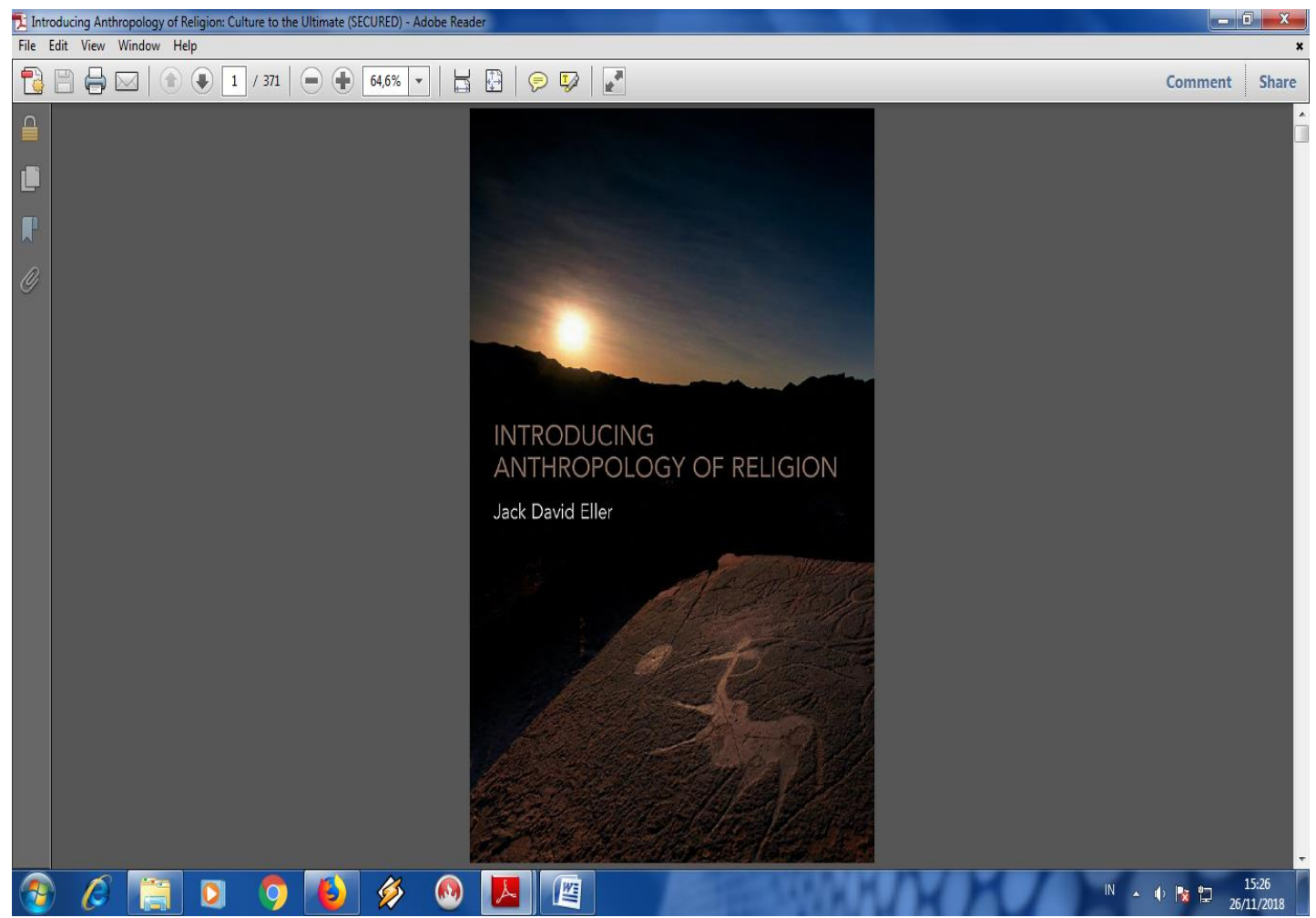

2. Halaman sampul dalam

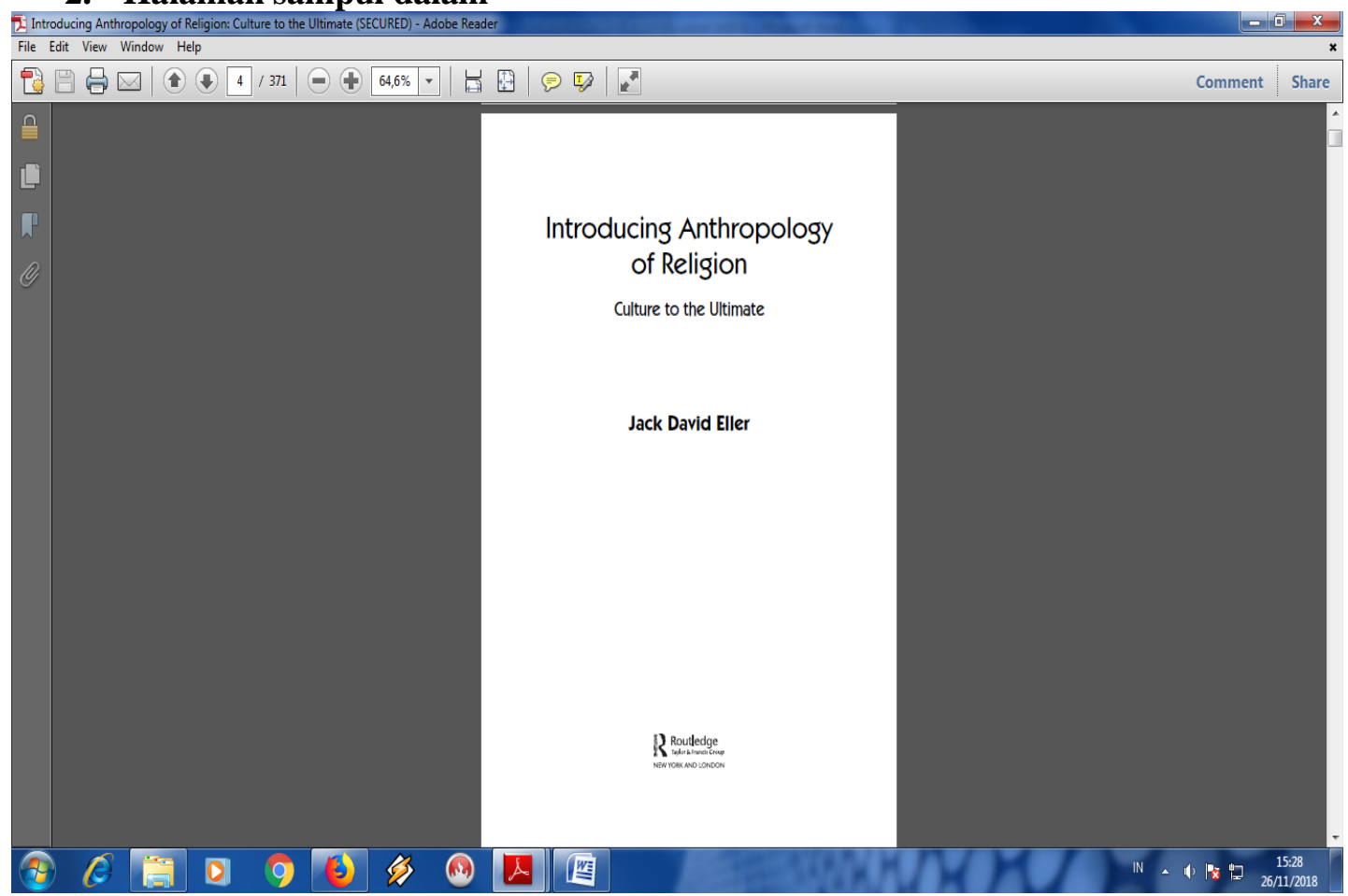

FUNDAMENTALISME AGAMA: Telaah Artikel "Religious Fundamentalism" dalam Buku Introducing Anthrophology of Religion; Culture of The Ultimate Karya Jack David Eller | 197 